\title{
Association of British Clinical Diabetologists (ABCD) position statement on the use of sodium-glucose cotransporter-2 (SGLT-2) inhibitors in type 1 diabetes
}

\author{
UMESH DASHORA ${ }^{1}$, DIPESH PATEL, ${ }^{2}$ ROB GREGORY, ${ }^{3}$ DINESH NAGI ${ }^{4}$ ON BEHALF OF THE ABCD \\ EXECUTIVE COMMITTEE
}

\begin{abstract}
SGLT-2 inhibitors are currently neither licensed nor recommended in people with type 1 diabetes. The management of type 1 diabetes consists essentially of insulin treatment, monitoring and education. SGLT-2 inhibitors can be a useful adjunct to insulin treatment in improving glycaemic control. They may also potentially be helpful in reducing cardiovascular and renal complications in people with type 1 diabetes. However, further studies will be needed to establish this. SGLT-2 inhibitors can cause diabetic ketoacidosis and certain circumstances appear to increase this risk. They should therefore be used with caution all the time and only under specialist supervision. Higher amputation rates have been reported with some SGLT-2 inhibitors and hence they should be used with caution in patients with peripheral vascular disease.
\end{abstract}

Br J Diabetes 2018;18:117-121

Key words: SGLT-2 inhibitors, type 1 diabetes, ketoacidosis, position statement

$A B C D$ recommendations for use of SGLT-2 inhibitors in type 1 diabetes

- SGLT-2 inhibitors are currently not licensed in people with type 1 diabetes. ABCD supports the NICE guidelines for management of type 1 diabetes. ${ }^{1}$

- SGLT-2 inhibitor treatment is not currently recommended in people with type 1 diabetes but may be a useful adjunct to

Conquest Hospital, Hastings, UK

Division of Medicine, University College London, UK

University Hospitals of Leicester NHS Trust, UK

4 Edna Coates Diabetes and Endocrine Unit, Pinderfields Hospital, Wakefield, UK

Address for correspondence: Dr Umesh Dashora Consultant Physician and Lead, Diabetes and Endocrinology, East Sussex Healthcare NHS Trust, UK

Tel: +44 (0)1424 755255

E-mail: u.dashora@nhs.net

Br J Diabetes 2018;18:117-121

https://doi.org/10.15277/bjd.2018.184 achieve better glycaemic control with added benefit of weight loss in patients who are inadequately controlled.

- $A B C D$ recommends that any use of SGLT-2 inhibitors in type 1 diabetes patients on insulin must be under regular supervision by a specialist clinician with careful monitoring and support from a diabetes team.

- Patients should be informed that diabetic ketoacidosis has been reported in patients taking SGLT-2 inhibitors, particularly those in whom the insulin dose was reduced by more than $20 \%$. Patients should be reminded of the precipitating factors for diabetic ketoacidosis (ie, excessive carbohydrate restriction, excessive alcohol, infections, surgical procedures and acute medical illness).

- As diabetes control improves with SGLT-2 inhibitors, the insulin dose may have to be reduced. Such reduction should be gradual and not exceed $10 \%$ of the dose at a time. Patients should have access to a blood ketone monitor and appropriate training in using it. Blood ketones should be checked if feeling unwell even when the capillary glucose levels are not particularly high. If the ketones are above $0.6 \mathrm{mmol} / \mathrm{L}$, medical help should be sought as the patient may require additional advice to prevent ketoacidosis and/or treatment with intravenous fluids and insulin.

- $\mathrm{ABCD}$ recommends stopping SGLT-2 inhibitors before major surgical procedures and in patients who are acutely ill. Patients should be informed that higher amputation rates and fractures have been reported in one trial with one of the SGLT-2 inhibitors (ie, canagliflozin) in type 2 diabetes.

- SGLT-2 inhibitors should be used with caution in patients with peripheral vascular disease and stopped if any signs of peripheral vascular insufficiency are detected.

- Patients should be informed that SGLT-2 inhibitors can cause mild diuresis and nocturia and they should maintain adequate hydration to prevent the effects of dehydration.

SGLT-2 inhibitors and their current licensed indications Sodium-glucose cotransporter-2 (SGLT-2) inhibitors are an established class of drugs which effectively lower glucose levels in people with type 2 diabetes, with additional cardiac and renal benefits in the Cardiovascular Outcome Trials. These drugs reduce blood glucose by preventing renal reabsorption of glucose, a mechanism 
which is insulin independent but glucose dependent. ${ }^{2}$ Additional positive effects on lowering blood pressure by natriuresis and weight loss might partly mediate the cardiovascular benefit recently observed in clinical trials in patients with type 2 diabetes, although other mechanisms are possible. ${ }^{3-6}$ Dapagliflozin was the first SGLT2 inhibitor to be approved for use in Europe in 2011 and in the UK in 2012. There are currently three SGLT-2 inhibitors licensed in the UK: dapagliflozin, canagliflozin and empagliflozin. Sotagliflozin is a dual SGLT inhibitor and will not be discussed in this article.

Currently, SGLT-2 inhibitors are licensed in people with type 2 diabetes but are neither licensed nor recommended in type 1 diabetes. Nevertheless, there is increasing off-label use of these agents in type 1 diabetes. This has prompted development of the following ABCD position statement on the use of SGLT-2 inhibitors in type 1 diabetes.

\section{Potential role in type 1 diabetes}

Optimal management of type 1 diabetes remains a challenge in the UK. Recent data show that the percentage of people achieving the National Institute for Health and Care Excellence (NICE) recommended targets i.e. $\mathrm{HbA}_{1 \mathrm{c}}<58 \mathrm{mmol} / \mathrm{mol}(7.5 \%), \mathrm{BP}<140 / 80 \mathrm{~mm}$ of $\mathrm{Hg}$, cholesterol $<5 \mathrm{mmol} / \mathrm{l}$ is $30.2 \%, 75.8 \%$ \& $69.3 \%$ respectively. All three targets were achieved only in $18.9 \%$ of the patients. $1,7,8$

There are considerable data showing a higher cardiovascular 9,10 and renal risk ${ }^{11}$ in people with type 1 diabetes. There is therefore scope for improving risk factor control by tighter glycaemic control with appropriate insulin therapy aided by potential adjunct therapy for people with type 1 diabetes. Extrapolating from the recent data in type 2 diabetes, SGLT-2 inhibitors may potentially be helpful in reducing cardiovascular and renal complications in people with type 1 diabetes. However, outcome studies will be needed to establish this.

The $A B C D$ position statement outlines the standards of care in people with type 1 diabetes..$^{12}$ Intensified insulin therapy is often used to control hyperglycaemia in type 1 diabetes on the basis of studies which showed a link between hyperglycaemia and micro and macrovascular complications of diabetes. ${ }^{13}$ This intensification, however, may increase the risk of hypoglycaemia, weight gain and associated adverse cardiovascular profile. ${ }^{14}$

Metformin is inexpensive and useful in some overweight people with type 1 diabetes but it does not improve $\mathrm{HbA}_{1 \mathrm{c}}$ in the long term. ${ }^{15,16}$ Glucagon-like peptide-1 (GLP-1) analogues and receptor agonists may be helpful in subgroups of people with type 1 diabetes but the data are limited. ${ }^{17}$ Dipeptidyl peptidase-4 (DPP4) inhibitors have not shown any consistent effect on glycaemic control or glucose variability in patients with type 1 diabetes..$^{18}$ In contrast, SGLT-2 inhibitors are oral glucose-lowering drugs with potential in this group of patients. ${ }^{19}$

\section{Evidence for SGLT-2 inhibitors in type 1 diabetes}

There is considerable emerging evidence for the use of SGLT-2 inhibitors in type 1 diabetes, which is summarised in brief in Table $1 .{ }^{20-26} \mathrm{~A}$ meta-analysis of three randomised controlled trials (RCTs) in patients with type 1 diabetes treated with SGLT-2 inhibitors versus placebo added to insulin showed significant reductions in fasting glucose (by $2.47 \mathrm{mmol} / \mathrm{L}$ ) and insulin dose
(-0.75 IU) without any increase in hypoglycaemia, infections or diabetic ketoacidosis (DKA) in the SGLT-2 inhibitor group. ${ }^{27} \mathrm{An}$ other subgroup meta-analysis of RCTs in a similar group showed significant reductions in $\mathrm{HbA}_{1 \mathrm{c}}(-1.30 \%)$, weight $(-1.3 \mathrm{~kg})$ and insulin dose $(-7.27 \mathrm{IU})$ without any increase in infections. DKA analysis was not performed. ${ }^{28}$ In a further RCT from a single centre, 30 patients with type 1 diabetes on liraglutide and insulin were put on additional dapagliflozin or placebo. ${ }^{29}$ In the dapagliflozin group $\mathrm{HbA}_{1 c}$ fell by $0.66 \%$ from $7.8 \%(p<0.01)$, with no change in the placebo group after 12 weeks.

The European Medicines Agency has accepted the application of a marketing authorisation variation for dapagliflozin for use as an oral adjunct treatment to insulin in people with type 1 diabetes. ${ }^{30}$

\section{Cautions in prescribing SGLT-2 inhibitors in type 1 diabetes}

\section{Risk of diabetic ketoacidosis (DKA)}

People with type 1 diabetes are characterised by their propensity to DKA in the absence of insulin. Insulin helps reduce glucose but also prevents lipolysis. SGLT-2 inhibitors reduce glucose but have been associated with reports of ketoacidosis in people with type 1 diabetes and some people with type 2 diabetes through mechanisms which are not yet fully understood. The current evidence is presented below.

A study based on the US Food and Drug Administration Adverse Event Reporting System (FAERS) showed that the proportional reporting ratio of DKA in patients on SGLT-2 inhibitors was 7.9, was higher for type 1 diabetes and in women, with a wide range of age and body weight. Duration of treatment varied and death was reported in 37 individuals (1.54\%). ${ }^{31}$

Peters et al reported a series of case reports of DKA in patients taking SGLT-2 inhibitors. Thirteen cases of DKA were observed in nine patients (seven with type 1 diabetes and two with type 2 diabetes). Four patients had recurrent episodes. ${ }^{32}$

A post hoc re-evaluation of 17,000 patients who participated in the canagliflozin development programme has been reported. Twelve cases of DKA were reported, four $(0.07 \%)$ in the canagliflozin $100 \mathrm{mg}$ group, six $(0.11 \%)$ in the canagliflozin 300 $\mathrm{mg}$ group and two $(0.03 \%)$ in the placebo comparator group. Six of the participants (50\%) were reported to have either type 1 diabetes or latent autoimmune diabetes of adults (LADA). ${ }^{33}$

Another study by Perkins et al is an eight-week open-label proof of concept trial using SGLT-2 inhibitors in type 1 diabetes. Two of the 40 patients with type I diabetes (5\%) had symptomatic ketosis or DKA. ${ }^{34}$ There have been a few other case reports of DKA in patients with type 1 diabetes who took SGLT-2 inhibitors. ${ }^{35-37}$

\section{Putative mechanism of ketogenesis}

The reason for the small but not insignificant rise in DKA in people taking SGLT-2 inhibitors is poorly understood. Several mechanisms have been suggested including excessive dose reduction of insulin, a tendency towards ketosis, a shift in substrate metabolism with increased reliance on free fatty acids and ketone bodies rather than glucose and pyruvate. ${ }^{38}$ Finally there is a 
Table 1 Summary of evidence for SGLT-2 inhibitors in type 1 diabetes

\begin{tabular}{|c|c|c|c|c|c|}
\hline $\begin{array}{l}\text { Author } \\
\text { (year) }\end{array}$ & $\begin{array}{l}\text { Patient features: } \\
\text { age (years), BMI } \\
\left(\mathrm{kg} / \mathrm{m}^{2}\right), \mathrm{n}\end{array}$ & $\begin{array}{l}\text { Type of study } \\
\text { and duration }\end{array}$ & $\begin{array}{l}\text { SGLT-2 inhibitor } \\
\text { used vs. placebo } \\
\text { plus insulin }\end{array}$ & Results & DKA (where reported) \\
\hline $\begin{array}{l}\text { Pieber } \\
(2015)^{21}\end{array}$ & $\begin{array}{l}\text { Age 18-65, } \\
\text { BMl } 25.7(n=75)\end{array}$ & RCT (4 weeks) & Empagliflozin 25 mg & $\begin{array}{l}\downarrow \text { insulin dose }(-0.98 \mathrm{IU}) \text {. No increase } \\
\text { in hypoglycaemia. } \uparrow \text { ketones in } 2 \\
\text { patients (not an adverse event) }\end{array}$ & None \\
\hline $\begin{array}{l}\text { Dandona } \\
(2017)^{22}\end{array}$ & $\begin{array}{l}\text { Age 18-75, } \\
\text { BMl } 28.3(n=833)\end{array}$ & RCT (24 weeks) & $\begin{array}{l}\text { Dapagliflozin } 5 \text { and } \\
10 \mathrm{mg}\end{array}$ & $\begin{array}{l}\downarrow \mathrm{HbA}_{1 \mathrm{c}}(-0.42 \% \text { and }-0.45 \%) \text {. } \\
\downarrow \text { insulin dose }(-8.8 \% \text { and } 13.2 \%) \text {. } \\
\downarrow \text { body weight }(-2.96 \% \text { and } 3.72 \%) \text {. } \\
\text { No increase in hypoglycaemia }(79 \% \text {, } \\
79 \% \text { and } 80 \%)\end{array}$ & $\begin{array}{l}\text { Similar in all groups } \\
5 \text { mg: } 4 \text { of } 277 \\
10 \text { mg: } 5 \text { of } 296 \\
\text { Placebo: } 3 \text { of } 260 \\
\text { In patients who had DKA, } \\
\text { insulin dose reduction vs. } \\
\text { placebo in the above groups } \\
\text { was }-8.9 \%,-25.3 \% \text { and } \\
-7.8 \% \text { at the time of DKA }\end{array}$ \\
\hline $\begin{array}{l}\text { Rodbard } \\
(2017)^{24}\end{array}$ & $\begin{array}{l}\text { Age } 25-65, \mathrm{BMl} \\
21-35(n=351)\end{array}$ & RCT (18 weeks) & $\begin{array}{l}\text { Canagliflozin } 100 \\
\text { and } 300 \mathrm{mg}\end{array}$ & $\begin{array}{l}\downarrow \text { mean glucose }(-1.2,-0.7) \text { with } \\
\text { more time spent within target glucose } \\
\text { range than outside }\end{array}$ & \\
\hline $\begin{array}{l}\text { Henry } \\
(2015)^{25}\end{array}$ & $\begin{array}{l}\text { Age } 25-65, \mathrm{BMl} \\
21-35(n=351)\end{array}$ & RCT (18 weeks) & $\begin{array}{l}\text { Canagliflozin } 100 \\
\text { and } 300 \mathrm{mg}\end{array}$ & $\begin{array}{l}\uparrow \text { proportion of patients achieving } \\
\mathrm{HbA} \mathrm{A}_{1 \mathrm{c}} \text { reduction of }>0.4 \% \text { without } \\
\text { any increase in body weight }(36.9 \% \\
\text { and } 41.4 \% \text { vs. } 4.5 \%)\end{array}$ & $\begin{array}{l}\text { † DKA }(4.3 \% \text { and } \\
6 \% \text { vs. } 0)\end{array}$ \\
\hline
\end{tabular}

possibility that ketogenesis could occur due to the direct action of SGLT-2 inhibitors on human pancreatic alpha cells increasing glucagon secretion. ${ }^{39,40}$ As the glucose concentrations in some of these patients can be close to target levels, the diagnosis of DKA can be delayed or missed.

\section{Effect of insulin dose reduction on ketosis}

Insulin deficiency seems to be related to ketoacidosis in patients with type 1 diabetes taking SGLT-2 inhibitors. A post hoc exploratory analysis of these patients has shown that ketone formation is greater when the insulin dose reduction is $>20 \%$ compared with an insulin dose reduction of $<20 \% .{ }^{41}$ Similarly, insulin pump failure and missed insulin doses were the most frequent risk factors in the cases of DKA seen in the most recent study. ${ }^{22}$ In another small study in patients with type 1 diabetes using liraglutide and SGLT-2 inhibitors, two patients developed DKA. Both patients had a reduction in insulin doses of $>20 \%$ and both events occurred within 48 hours of dose titration of dapagliflozin from $5 \mathrm{mg}$ to $10 \mathrm{mg}$ daily. ${ }^{30}$ In addition, one patient had consumed a large amount of alcohol which is likely to be a factor in the development of euglycaemic ketoacidosis.

\section{Risk of amputations and stroke}

The risk of amputations and stroke remains unclear with the available current evidence. Canagliflozin in people with type 2 diabetes was associated with a higher rate of amputations mainly at the level of the toe and metatarsals. ${ }^{5}$ There was a higher rate of fractures in the CANVAS study but not in the CANVAS-R study. ${ }^{5}$ A recent metaanalysis has confirmed an excess risk of amputations with canagliflozin but not with other SGLT-2 inhibitors. ${ }^{42}$ Numerically, empagliflozin increased but canagliflozin reduced strokes in patients with type 2 diabetes, although both numbers were not significant and a subsequent meta-analysis is reassuring. 3,5,43

\section{Risk of dehydration}

As the mechanism of action of SGLT-2 inhibitors leads to glycosuria, they act as mild diuretics. Precautions should therefore be taken in individuals who are at risk of dehydration and acute kidney injury because of old age or co-morbidities.

\section{Conclusions}

SGLT-2 inhibitors are currently not licensed or recommended in people with type 1 diabetes. However, they may be an effective adjunct 


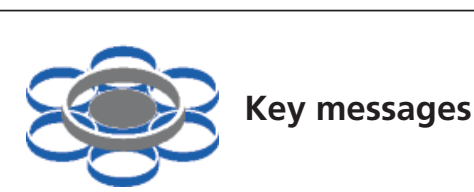

- SGLT-2 inhibitors are currently neither licensed nor recommended in people with type 1 diabetes.

- While the management of type 1 diabetes requires insulin treatment, monitoring and education, SGLT-2 inhibitors may be a potential adjunct in improving glycaemic control with the additional benefit of weight loss.

- SGLT-2 inhibitors may be associated with diabetic ketoacidosis and certain circumstances appear to increase this risk. SGLT-2 inhibitors should therefore be used with caution and with regular monitoring.

- Higher amputation rates and fractures have been reported in one SGLT-2 inhibitor outcome trial and hence these drugs should be used with caution in patients with peripheral vascular disease, foot ulcers or previous amputations and stopped if there are any signs of vascular insufficiency in the lower limbs.

in improving glycaemic control in people with type 1 diabetes who are on insulin treatment.

SGLT-2 inhibitors are well tolerated with very few side effects including urinary and genital infections, dehydration and DKA. In general, the rate and prevalence of DKA in people with type 1 diabetes taking SGLT-2 inhibitors is too low to quantify exactly but may not be insignificant. In patients with type 1 diabetes taking SGLT-2 inhibitors, it would make pragmatic sense to anticipate and monitor for possible DKA in situations known to precipitate metabolic decompensation (injury, infections, myocardial infarction, stroke, insulin deficiency, other stressful events and catabolic states). There should be prompts to identify patients attending emergency departments or medical admissions units who are prescribed SGLT2 inhibitors to warn of the possibility of euglycaemic DKA where the patient may be in DKA despite normal glucose levels. SGLT-2 inhibitors should be stopped in patients who are acutely ill or are admitted for elective surgery. SGLT-2 inhibitors should also be discontinued in patients who have developed DKA and should not be re-challenged unless a clear alternative cause of DKA is identified. Insulin doses should not be reduced $>20 \%$ if SGLT-2 inhibitors are added to insulin regimens.

$A B C D$ recommends that regular monitoring of blood glucose and ketones should be undertaken in patients taking these drugs to avoid hypoglycaemia as well as ketosis. The ABCD position statement may need revision after further results of the Dapagliflozin Evaluation in Patients with Inadequately Controlled Type 1 Diabetes trials (DEPICT 1 and 2) become available. DEPICT 1 was a double-blind, randomised, parallel-controlled, three-arm, phase 3 multicentre study carried out at 143 sites in 17 countries and reported results at 24 weeks. DEPICT 2 will provide safety and efficacy data at 52 weeks. ${ }^{44}$

\section{Conflict of interest None. \\ Funding None.}

\section{References}

1. National Institute for Health and Care Excellence (NICE). Type 1 diabetes in adults: diagnosis and management. NICE guideline [NG17]. London, 2016. https://www.nice.org.uk/guidance/ng17 (accessed 17 May 2018)

2. Vallon $\mathrm{V}$. The mechanisms and therapeutic potential of SGLT2 inhibitors in diabetes mellitus. Annu Rev Med 2015;66:255-70. https://doi.org/10.1146/annurev-med-051013-110046

3. Zinman B, Wanner C, Lachin JM, et al. Empagliflozin, cardiovascular outcomes, and mortality in type 2 diabetes. N Engl J Med 2015;373:211728. https://doi.org/10.1056/NEJMoa1504720

4. Vallon V, Thomson SC. Diabetes mellitus: Cardiovascular and renal benefits of SGLT2 inhibition: insights from CANVAS. Nat Rev Nephrol 2017;13:5178. https://doi.org/10.1038/nrneph.2017.113

5. Neal B, Perkovic V, Mahaffey KW, et al. Canagliflozin and cardiovascular and renal events in type 2 diabetes. N Engl J Med 2017;377:644-57. https://doi.org/10.1056/NEJMoa1611925

6. Wanner C, Inzucchi SE, Lachin JM, et al. Empagliflozin and progression of kidney disease in type 2 diabetes. N Engl J Med 2016;375:323-34. https://doi.org/10.1056/NEJMoa1515920

7. National Institute for Health and Care Excellence (NICE). Cardiovascular disease: risk assessment and reduction, including lipid modification. Clinical guideline [CG181]. London, 2016. https://www.nice.org.uk/guidance/ cg181 (accessed 17 May 2018).

8. NHS digital. National Diabetes Audit 2016-17. https://files.digital.nhs.uk/ pdf/s/k/national_diabetes_audit_2016-17_report_1_care_processes_and_ treatment targets.pdf (accessed 17 July 2018).

9. Armstrong AC, Ambale-Venkatesh B, Turkbey E, et al. Association of cardiovascular risk factors and myocardial fibrosis with early cardiac dysfunction in type 1 diabetes: the Diabetes Control and Complications Trial/Epidemiology of Diabetes Interventions and Complications Study. Diabetes Care 2017;40:405-11. https://doi.org/10.2337/dc16-1889

10. Matuleviciene-Anängen $V$, Rosengren A, Svensson AM, et al. Glycaemic control and excess risk of major coronary events in persons with type 1 diabetes Heart 2017;103:1687-95. https://doi.org/10.1136/heartjnl-2016-311050

11. Gagnum V, Stene LC, Leivestad T, Joner G, Skrivarhaug T. Long-term mortality and end-stage renal disease in a type 1 diabetes population diagnosed at age 15-29 years in Norway. Diabetes Care 2017:40:38-45. https://doi.org/10.2337/dc16-1213.

12. Sharp P, Kilvert A, Dashora $U$, et al, for the Association of British Clinical Diabetologists (ABCD). Standards of care for management of adults with type 1 diabetes. https://abcd.care/sites/abcd.care/files/site_uploads/ Type_1_standards_of_care.pdf (accessed 17 May 2018).

13. Nathan DM, for the DCCT/EDIC Research Group. The Diabetes Control and Complications Trial/Epidemiology of Diabetes Interventions and Complications Study at 30 years: overview. Diabetes Care 2014;37:9-16. https://doi.org/10.2337/dc13-2112

14. Purnell JQ, Hokanson JE, Marcovina SM, Steffes MW, Cleary PA, Brunzell JD. Effect of excessive weight gain with intensive therapy of type 1 diabetes on lipid levels and blood pressure: results from the DCCT. JAMA 1998;280:140-6. https://doi.org/10.1001/jama.280.2.140

15. Vella S, Buetow L, Royle P, Livingstone S, Colhoun HM, Petrie JR. The use of metformin in type 1 diabetes: a systematic review of efficacy. Diabetologia 2010;53:809-20. https://doi.org/10.1007/s00125-009-1636-9

16. Staels F, Moyson C, Mathieu C. Metformin as add-on to intensive insulin therapy in type 1 diabetes mellitus. Diabetes Obes Metab 2017;19:14637. https://doi.org/10.1111/dom.12948

17. Gillani SM, Singh BM. The use of liraglutide, a GLP-1 agonist, in obese people with type 1 diabetes. $B r$ J Diabetes 2014;14:98-101. https://doi.org/10.15277/bjdvd.2014.022

18. Guo H, Fang C, Huang Y, Pei Y, Chen L, Hu J. The efficacy and safety of DPP4 inhibitors in patients with type 1 diabetes: a systematic review and meta-analysis. Diabetes Res Clin Pract 2016;121:184-91. https://doi.org/10.1016/j.diabres.2016.08.022

19. Dellepiane S, Nasr MB, Assi E, et al. Sodium glucose cotransporter inhibitors in type 1 diabetes. Pharmacol Res 2018;133:1-8. https://doi.org/10.1016/j.phrs.2018.04.018 [Epub ahead of print] 
20. Henry RR, Rosenstock J, Edelman S, et al. Exploring the potential of the SGLT2 inhibitor dapagliflozin in type 1 diabetes: a randomized, double-blind, placebo-controlled pilot study. Diabetes Care 2015;38:412-19. https://doi.org/10.2337/dc13-2955

21. Pieber TR, Famulla S, Eilbracht J, et al. Empagliflozin as adjunct to insulin in patients with type 1 diabetes: a 4-week, randomized, placebo-controlled trial (EASE-1). Diabetes Obes Metab 2015;17:928-35. https://doi.org/10.1111/dom.12494

22. Dandona P, Mathieu C, Phillip M, et al; DEPICT-1 Investigators. Efficacy and safety of dapagliflozin in patients with inadequately controlled type 1 diabetes (DEPICT-1): 24 week results from a multicentre, double-blind, phase 3, randomised controlled trial. Lancet Diabetes Endocrinol 2017;5:864-76. https://doi.org/10.1016/\$2213-8587(17)30308-X

23. Famulla S, Pieber TR, Eilbracht J, et al. Glucose exposure and variability with empagliflozin as adjunct to insulin in patients with type 1 diabetes: continuous glucose monitoring data from a 4-week, randomized, placebocontrolled trial (EASE-1). Diabetes Technol Ther 2017;19:49-60. https://doi.org/10.1089/dia.2016.0261

24. Rodbard HW, Peters AL, Slee A, Cao A, Traina SB, Alba M. The effect of canagliflozin, a sodium glucose cotransporter 2 inhibitor, on glycemic end points assessed by continuous glucose monitoring and patient-reported outcomes among people with type 1 diabetes. Diabetes Care 2017;40:17180. https://doi.org/10.2337/dc16-1353

25. Henry RR, Thakkar P, Tong C, Polidori D, Alba M. Efficacy and safety of canagliflozin, a sodium-glucose cotransporter 2 inhibitor, as add-on to insulin in patients with type 1 diabetes. Diabetes Care 2015;38:2258-65. https://doi.org/10.2337/dc15-1730

26. Biester $T$, Aschemeier $B$, Fath $M$, et al. Effects of dapagliflozin on insulinrequirement, glucose excretion and $\beta$-hydroxybutyrate levels are not related to baseline HbA1c in youth with type 1 diabetes. Diabetes Obes Metab 2017;19:1635-9. https://doi.org/10.1111/dom.12975

27. Yang Y, Pan H, Wang B, Chen S, Zhu H. Efficacy and safety of SGLT2 inhibitors in patients with type 1 diabetes: a meta-analysis of randomized controlled trials. Chinese Med Sci J 2017;32:22-7.

https://doi.org/10.24920/J1001-9242.2007.003

28. Yang $Y$, Chen S, Pan H, et al. Safety and efficiency of SGLT2 inhibitor combining with insulin in subjects with diabetes: systematic review and metaanalysis of randomized controlled trials. Medicine (Baltimore) 2017;96 e6944. https://doi.org/10.1097/MD.0000000000006944

29. Kuhadiya ND, Ghanim H, Mehta A, et al. Dapagliflozin as additional treatment to liraglutide and insulin in patients with type 1 diabetes. J Clin Endocrinol Metab 2016;101:3506-15. https://doi.org/10.1210/jc.2016-1451

30. European Pharmaceutical Review. EMA accepts marketing authorisation variation for Forxiga in adults with type-1 diabetes. https://www.europeanpharmaceuticalreview.com/news/73381/ema-forxiga-type-1-diabetes (accessed 16 May 2018).

31. Fadini GP, Bonora BM, Avogaro A. SGLT2 inhibitors and diabetic ketoacidosis: data from the FDA Adverse Event Reporting System. Diabetologia
2017;60:1385-9. https://doi.org/10.1007/s00125-017-4301-8

32. Peters AL, Buschur EO, Buse JB, Cohan P, Diner JC, Hirsch IB. Euglycemic diabetic ketoacidosis: a potential complication of treatment with sodium-glucose cotransporter 2 inhibition. Diabetes Care 2015;38:1687-93. https://doi.org/10.2337/dc15-0843

33. Erondu N, Desai M, Ways K, Meininger G. Diabetic ketoacidosis and related events in the Canagliflozin Type 2 Diabetes Clinical Program. Diabetes Care 2015;38:1680-6. https://doi.org/10.2337/dc15-1251

34. Perkins BA, Cherney DZ, Partridge $H$, et al. Sodium glucose cotransporter 2 inhibition and glycemic control in type 1 diabetes: results of an 8-week openlabel proof-of concept trial. Diabetes Care 2014;37:1480-3. https://doi.org/10.2337/dc13-2338

35. Roman R, Pereyra M, Ramirez C. Adolescent with type 1 diabetes on insulin and dapaglifozin a SGLT2 inhibitor developed an euglycemic diabetic ketosis. Horm Res Paediatr 2016;86:48.

36. Roman R, Valdivia N, Ruiz S. Overweight adolescents with type 1 diabetes may decrease body mass index, insulin dose and glucose variability on dapagliflozin, a SGLT2 inhibitor. Horm Res Paediatr 2016;86:73.

37. Bader N, Mirza L. Euglycemic diabetic ketoacidosis in a 27 year-old female patient with type-1-diabetes treated with sodium-glucose cotransporter-2 (SGLT2) inhibitor canagliflozin. Pak J Med Sci 2016;32:786-8. https://doi.org/10.12669/pjms.323.9201

38. Ferrannini E, Baldi S, Frascerra $S$, et al. Shift to fatty substrate utilization in response to sodium-glucose cotransporter 2 inhibition in subjects without diabetes and patients with type 2 diabetes. Diabetes 2016;65:1190-5. https://doi.org/10.2337/db15-1356

39. Bonner C, Kerr-Conte J, Gmyr V, et al. Inhibition of the glucose transporter SGLT2 with dapagliflozin in pancreatic alpha cells triggers glucagon secretion. Nat Med 2015;21:512-17. https://doi.org/10.1038/nm.3828

40. Maruyama $H$, Hisatomi A, Orci L, et al. Insulin within islets is a physiologic glucagon release inhibitor. J Clin Invest 1984;74:2296-9. https://doi.org/10.1172/JCI111658

41. Henry RR, Dandona P, Pettus J, Mudaliar S, Xu J, Hansen L. Dapagliflozin in patients with type 1 diabetes: a post hoc analysis of the effect of insulin dose adjustments on 24 hour continuously monitored mean glucose and fasting $\beta$ hydroxybutyrate levels in a phase lla pilot study. Diabetes Obes Metab 2017;19:814-21. https://doi.org/10.1111/dom.12882

42. Li D, Yang JY, Wang T, Shen S, Tang H. Risks of diabetic foot syndrome and amputation associated with sodium glucose co-transporter 2 inhibitors: a meta-analysis of randomized controlled trials. Diabetes Metab 2018 Feb. https://doi.org/10.1016/j.diabet.2018.02.001 (accessed 17 May 2018)

43. Guo M, Ding J, Li J, et al. SGLT2 inhibitors and stroke risk in patients with type 2 diabetes: a systematic review and meta-analysis. Diabetes Obes Metab 2018 Mar. https://doi.org/10.1111/dom.13295 (accessed 17 May 2018)

44. National Institutes of Health. Dapagliflozin evaluation in patients with inadequately controlled type 1 diabetes (DEPICT 2). http://clinicaltrials.gov/show/ NCT02460978 (accessed 17 May 2018). 